\title{
Dessecação de espécies de cobertura do solo com formulações de glyphosate ${ }^{1}$
}

\author{
Desiccation species of ground cover with glyphosate formulations
}

Fábio Henrique Krenchinski ${ }^{2}$; Leandro Paiola Albrecht ${ }^{3}$; Leandro Rafael Krenchinski ${ }^{4}$; Henrique Fabricio Placido ${ }^{2}$; Jean Elisier Reckziegel ${ }^{2}$; Fernando Henrique Ecco $^{2}$

Resumo - O manejo das espécies de cobertura pode ser realizado por métodos mecânicos ou químicos. No método químico são utilizados herbicidas não seletivos principalmente do grupo do glyphosate. O objetivo do presente trabalho foi avaliar a fitotoxicidade e a eficiência agronômica de duas formulações com princípio ativo glyphosate na dessecação em espécies de cobertura do solo. O presente trabalho foi conduzido no campo no município de Marechal Cândido Rondon/PR. O delineamento experimental foi de blocos ao acaso com quatro repetições com esquema fatorial de $2 \times 5$ (formulações x espécies), no qual as espécies constituíram-se de aveiabranca, aveia-preta, azevém, ervilhaca e nabo-forrageiro, dessecados por dois herbicidas: Zapp QI $^{\circledR}$ (ZQ) e Glyphosate 480 Agripec $^{\circledR}(\mathrm{GA})$. Foram avaliados fitotoxicidade e eficiência agronômica das espécies de cobertura. Zapp Qi ${ }^{\circledR}$ proporcionou maior fitotoxicidade e eficiência agronômica nas espécies de cobertura em relação ao Glyphosate 480 Agripec $^{\circledR}$. O Zapp Qi ${ }^{\circledR}$ aos 32 dias após a dessecação apresentou os maiores valores de eficiência agronômica. A única espécie que apresentou 100\% de eficiência agronômica foi o nabo-forrageiro.

Palavras-chaves: herbicidas, adubação verde, manejo

Abstract - The management of coverage species may be accomplished by mechanical or chemical methods. In chemical method nonselective herbicides are used mainly the ones belonging to glyphosate group. The objective of this study was to evaluate phytotoxicity and agronomic efficacy of two formulations with active ingredient glyphosate over desiccation in ground cover species. The present study was conducted in field conditions in Marechal Candido Rondon County, Parana State. Experimental design used was randomized complete blocks with four repetitions in factorial scheme $2 \times 5$ (formulations $x$ species), in that the species were white oat, black oat, ryegrass, common vetch and oilseed radish, desiccated by two herbicides: Zapp $\mathrm{Qi}^{\circledR}$ (ZQ) and Glyphosate 480 Agripec $^{\circledR}$ (GA). Phytotoxicity and agronomic efficacy of coverage species were evaluated. Zapp Q ${ }^{\circledR}{ }^{\circledR}$ has provided greater phytotoxicity and agronomic efficacy of coverage species when compared to Glyphosate 480 Agripec ${ }^{\circledR}$. Zapp Qi ${ }^{\circledR}$ at 32 days after desiccation presented the highest values of agronomic efficiency. The only specie that presented $100 \%$ of efficacy was oilseed radish.

Keywords: herbicides, green manure, management

\footnotetext{
${ }^{1}$ Recebido para publicação em 30/08/2012 e aceito em 21/02/2014.

2 Acadêmicos de Agronomia pela Universidade Federal do Paraná - Setor Palotina. R. Pioneiro, 2153, Jardim Dallas, CEP 85950-000. Palotina, PR, Brasil. E-mail: <fabiohk2@gmail.com; placido.agronomia@gmail.com; jeanelieser@gmail.com; fernandohecco@hotmail.com>.

${ }^{3}$ Professor Adjunto da Universidade Federal do Paraná - Setor Palotina. R. Pioneiro, 2153, Jardim Dallas, CEP 85950-000. Palotina, PR, Brasil. E-mail: <lpalbrecht@yahoo.com.br>.

${ }^{4}$ Técnico em Agropecuária. Universidade Federal do Paraná - Setor Palotina. R. Pioneiro, 2153, Jardim Dallas, CEP 85950-000. Palotina, PR, Brasil. E-mail: <krenchinski@hotmail.com>.
} 


\section{Introdução}

Cada vez mais ocorrem preocupações com a rotação de culturas e a deposição de matéria orgânica no solo, desse modo, muitos produtores tem aderido ao cultivo de espécies vegetais que visam alta produção de matéria seca, para fins de cobertura do solo. Segundo Amado et al. (2001) e Perin et al. (2004) essa técnica é utilizada desde os primórdios das civilizações, que além de propiciar uma cobertura do solo, são capazes de reciclar nutrientes e realizar a fixação biológica de nitrogênio no caso das leguminosas. Também são importantes quando usadas para evitar a erosão do solo, entre uma série de outras características que favorecem os cultivos posteriores a essas plantas. As plantas de cobertura são importantes no processo de rotação de culturas onde entram como alternativa.

A área cultivada no sistema de plantio direto tem aumentado rapidamente no Brasil, correspondendo a 50\% da área cultivada com culturas produtoras de grãos. Nesse sistema, a época de dessecação e a escolha da espécie vegetal de cobertura são fatores que alteram tanto a fertilidade do solo (Calonego et al., 2005; Rosolem et al., 2005) como o desenvolvimento da cultura comercial, permitindo a exploração do solo de modo conservacionista e com sustentabilidade da produtividade agrícola. Os principais benefícios proporcionados às propriedades químicas, físicas e biológicas do solo em sistema de plantio direto são consequência do aumento da matéria orgânica em razão da deposição da cobertura vegetal no solo Miyazawa et al. (2000).

O controle das plantas de cobertura antes da semeadura é comumente chamado de manejo. Esse manejo das espécies de cobertura pode ser realizado por métodos mecânicos ou químicos. No método químico, utilizam-se basicamente herbicidas sistêmicos de ação total, que não possuem seletividade, como o glyphosate que apresenta bons resultados de controle. (Souza, et al., 2000; Mello, 2002; Furlani et al., 2007). O glyphosate é um herbicida pós-emergente, pertencente ao grupo químico das glicinas substituídas, classificado como não-seletivo e de ação sistêmica. Apresenta amplo espectro de ação, o que possibilita excelente controle de plantas daninhas anuais ou perenes, tanto de folhas largas como estreitas (Galli \& Montezuma, 2005). No mercado tem-se a possibilidade de escolha por dois ingredientes ativos, com equivalente ácido a base de sal de potássio e outro com sal de isopropilamina.

Um dos aspectos de grande relevância para a dessecação é o controle efetivo e total das espécies de cobertura. Alguns trabalhos evidenciam o uso de glyphosate como uma das melhores opções para a dessecação das espécies de cobertura (Constantin et al., 2008; Monquero et al., 2010; Zagonel \& Marochi, 2004), porém a escassez de trabalhos que relatam a avaliação de eficiência de dessecação de espécies de cobertura com glyphosate, usando os dois tipos de sais (presentes no mercado) como ingrediente ativo.

O objetivo do presente trabalho foi avaliar a fitotoxicidade e a eficiência agronômica de dois herbicidas com o princípio ativo glyphosate, formulados com sais distintos, na dessecação em espécies utilizadas como cobertura do solo.

\section{Material e Métodos}

O presente trabalho foi realizado a campo no município de Marechal Cândido Rondon - PR, em um solo classificado como Latossolo Vermelho eutroférrico de textura muito argilosa (Embrapa, 2006) apresentando as seguintes características: $\mathrm{pH}\left(\mathrm{CaCl}_{2}\right)$ de 5,6; M.O de $36,55 \mathrm{~g} \mathrm{dm}^{-3}$; P de 19,40 mg dm${ }^{-3}$; 1,$68 ; 7,86 ; 0,00$ por $\mathrm{cmol}_{\mathrm{c}} \mathrm{dm}^{-3} ; \mathrm{K}, \mathrm{Ca}, \mathrm{Al}$, respectivamente. $\mathrm{O}$ clima que a região apresenta é o Cfa, de acordo com a classificação de Köppen. (Köppen \& Geiger, 1928). 
$\mathrm{O}$ delineamento experimental utilizado foi de blocos ao acaso com quatro repetições, em esquema fatorial de $2 \times 5$ (formulações $\mathrm{x}$ espécies); no qual as espécies constituíram-se de aveia-branca (Avena sativa L.), aveia-preta (Avena stringosa), azevém (Lollium multiflorum), ervilhaca (Vicia sativa) e naboforrageiro (Raphanus sativus L.), dessecados por duas formulações comerciais, constituídas por Zapp $\mathrm{QI}^{\circledR}(\mathrm{ZQ})$ a base de sal de potássio e Glyphosate 480 Agripec $^{\circledR}$ (GA), por sal de isopropilamina.

A semeadura das espécies de cobertura ocorreu na primeira quinzena de maio 2011 e foi realizada sem adubação. $\mathrm{O}$ arranjo espacial foi de $20 \mathrm{~cm}$ de entre linhas para todas as culturas, no qual para A. sativa L., A. stringosa, $L$. multiflorum, $V$. sativa e $R$. sativus L., o número de sementes por metro linear foi de 55 , $60,240,30$ e 20 , respectivamente.

Ao pleno florescimento as plantas foram dessecadas com Glyphosate (Zapp QI ${ }^{\circledR} \mathrm{e}$ Glyphosate 480 Agripec $\left.^{\circledR}\right)$ na dose de 1.080 gramas de equivalente ácido por ha (g e.a.ha ${ }^{-1}$, as aplicações foram realizadas utilizando-se um pulverizador costal de pressão constante à base de O2, com ponta do tipo leque XR 110-02 e pressão de $2,0 \mathrm{kgf} \mathrm{cm}^{-2}$, o que proporcionou volume correspondente a 200 litros de calda por hectare. Avaliações de fitotoxicidade e índice de eficácia agronômica foram realizados aos 4, 8, 16 e 32 dias após a dessecação (DAD).

$\mathrm{Na}$ avaliação de fitotoxicidade as plantas foram avaliadas de forma visual empregando uma escala visual de 1 a 9 , na qual 1 (um) representa "sem sintoma de fitotoxicidade aparente" e o 9 (nove) "morte total da planta" (EWRC, 1964). Da mesma forma e datas das avaliações de fitotoxicidade efetuou-se a análise de eficiência agronômica, empregando a escala percentual; onde zero (0\%) representa nenhum controle e $100 \%$ a morte total das plantas, (SBCPD, 1995).

As médias dos dados de fitotoxicidade foram transformados pelo método de raiz quadrado, e as médias de todos os tratamentos foram comparadas pelo teste de Tukey $(\mathrm{p} \leq 0,05)$, com auxílio do programa computacional Sisvar (Ferreira, 1999).

\section{Resultados e Discussão}

De maneira geral, as épocas de avaliação de fitotoxicidade do produto dentro de cada espécie de cobertura o ZQ foi significativamente superior ao GA (Tabela 1). Isto se deve a diferença no ingrediente ativo do glyphosate. Para ZQ o ingrediente ativo é o sal de Potássio, enquanto que para o GA o ingrediente ativo é sal de isopropilamina, supostamente pelo fato do sal de potássio apresentar melhor eficiência de absorção e translocação dentro da planta. A maior eficiência do sal de potássio pode ser comprovada por Jakelaitis et al. (2003) que ao realizar um experimento com simulação de chuva observou o sal de potássio como o único tratamento com controle favorável da espécies estudada após o intervalo de uma hora sem chuva simulada, sendo esse resultado foi significativo superior em relação as demais formulações de glyphosate.

Aos quatro dias após a dessecação (DAD) para o ZQ a espécie que apresentou maior fitotoxicidade diferindo significativamente das demais, foi a aveiabranca. Aos dezesseis dias após a aplicação para o herbicida GA a espécie nabo-forrageiro apresentou maior fitotoxicidade diferindo significativamente da espécie azevém. Com isso o nabo forrageiro pode ser considerado uma planta mais suscetível ao glyphosate, enquanto que o azevém pode ser considerado menos suscetível já que apresenta em algumas regiões do Rio Grande do Sul biótipos resistentes ao glyphosate (Roman et al., 2004). Aos 32 DAD para o ZQ somente o naboforrageiro e aveia-branca apresentaram dessecação total, mas não diferiram significativamente das demais espécies. Para GA nenhuma planta de cobertura apresentou dessecação total. Ainda aos 32 dias ZQ e GA 
não diferiram significativamente para as seguintes espécies: nabo-forrageiro e azevém, já para as demais espécies ocorreu diferença significativa entre os produtos, demonstrando que para aveia-preta, aveia-branca e ervilhaca o produto ZQ proporciona maiores valores de fitotoxicidade consequentemente maior controle dessas espécies.

Tabela 1. Fitotoxicidade em espécies de cobertura dessecadas com Zapp QI ${ }^{\circledR}$ (ZQ) e Glyphosate 480 Agripec $^{\circledR}$ (GA), no município de Marechal Cândido Rondon/PR.

\begin{tabular}{|c|c|c|c|c|c|c|c|c|}
\hline \multicolumn{9}{|c|}{ Avaliações de Fitotoxicidade } \\
\hline & \multicolumn{2}{|c|}{$4 \mathrm{DAD}^{1 /}$} & \multicolumn{2}{|c|}{$8 \mathrm{DAD}$} & \multicolumn{2}{|c|}{16 DAD } & \multicolumn{2}{|c|}{$32 \mathrm{DAD}$} \\
\hline Tratamentos & ZQ & GA & ZQ & GA & $\mathrm{ZQ}$ & GA & ZQ & GA \\
\hline nabo-forrageiro & $1,7 \mathrm{Ba}$ & $1,4 \mathrm{Ab}$ & $5,0 \mathrm{ABa}$ & $4,0 \mathrm{Aa}$ & $8,0 \mathrm{Aa}$ & $6,7 \mathrm{Ab}$ & $9,00 \mathrm{Aa}$ & $8,0 \mathrm{ABa}$ \\
\hline aveia-preta & $1,7 \mathrm{Ba}$ & $1,4 \mathrm{Ab}$ & $4,0 \mathrm{Ba}$ & $3,0 \mathrm{Ab}$ & 7,7Aa & $5,5 \mathrm{ABb}$ & $8,75 \mathrm{Aa}$ & $7,0 \mathrm{Cb}$ \\
\hline azevém & $1,7 \mathrm{Ba}$ & $1,4 \mathrm{Ab}$ & $4,7 \mathrm{ABa}$ & $3,2 \mathrm{Ab}$ & $6,5 \mathrm{Aa}$ & $4,7 \mathrm{Bb}$ & $8,75 \mathrm{Aa}$ & $8,2 \mathrm{Aa}$ \\
\hline aveia-branca & 2,0Aa & $1,4 \mathrm{Ab}$ & $6,0 \mathrm{Ba}$ & $3,5 \mathrm{Ab}$ & 7,7Aa & $5,7 \mathrm{ABb}$ & $9,0 \mathrm{Aa}$ & $8,0 \mathrm{ABb}$ \\
\hline ervilhaca & $1,7 \mathrm{Ba}$ & $1,4 \mathrm{Ab}$ & $4,2 \mathrm{ABa}$ & $3,0 \mathrm{Ab}$ & $7,0 \mathrm{Aa}$ & $5,7 \mathrm{ABb}$ & $8,5 \mathrm{Aa}$ & $7,2 \mathrm{BCb}$ \\
\hline $\mathrm{CV} \%$ & \multicolumn{2}{|c|}{1,75} & \multicolumn{2}{|c|}{8,59} & \multicolumn{2}{|c|}{5,63} & \multicolumn{2}{|c|}{2,75} \\
\hline
\end{tabular}

* Letras maiúsculas diferem entre si nas colunas e letras minúsculas nas linhas, pelo teste de Tukey $(\mathrm{p}<0,05) .{ }^{11}$ dias após a dessecação (DAD).

Para a avaliação de eficiência agronômica dos produtos dentro de cada tratamento, novamente o herbicida ZQ mostrou-se significativamente superior ao GA (Tabela 2). Jakelaitis et al. (2003), avaliando diferentes formulações de glyphosate em condições de chuva, constatou-se que com uma hora depois da aplicação com chuva o ZQ proporcionou o melhor controle na espécie estuda, levando-nos a afirmar que sua absorção é mais rápida que de outras formulações, constituindo a uma dessecação mais rápida. $\mathrm{O}$ mesmo aconteceu em trabalho realizado por Martini et al. (2003), na aplicação de glyphosate potássico em Brachiaria plantaginea, Brachiaria decumbens e Digitaria horizontalis, onde a incidência de chuva uma horas após a aplicação, a média de controle foi de $40 \%$ aos 14 dias após o tratamento, e atingiu $65 \%$ em 28 dias, sobressaindo em relação às demais formulações.

Em relação ao produto dentro de cada espécies nos diferentes dias de avaliação, aos 4 DAD a aveia-preta e o azevém tiveram eficiência agronômica significativamente maior que os demais tratamentos para o herbicida ZQ. O mesmo aconteceu para o GA, porém com menor índice de eficiência, onde os piores índices de eficiência foram identificados com a ervilhaca para ambos herbicidas. Já aos 8 DAD, a aveia-preta apresentou o maior controle diferindo significativamente dos demais tratamentos para os dois produtos utilizados, onde novamente os piores índices de eficiência foi com a espécie ervilhaca, para ambos os herbicidas. Segundo Martini et al. (2003), os melhores resultados e controle aparecem de forma mais evidente em algumas espécies, devido a maior suscetibilidade das espécies a molécula de glyphosate.

Aos 16 DAD, o nabo-forrageiro apresentou diferença significativa entre os demais tratamentos com relação as avaliações aos 4 e 8 DAD, nos quais a aveia-preta apresentava melhor eficiência. $\mathrm{O}$ naboforrageiro apresentou-se com melhor eficiência para os dois herbicidas, assim como mais uma vez a ervilhaca apresentou a menor eficiência agronômica. Aos 32 DAD, para ZQ o naboforrageiro apresentou $100 \%$ de eficiência agronômica e aveia-preta 99\%, essas duas espécies diferiram das demais para ZQ, já para o herbicida GA a aveia-preta foi superior às demais espécies. A ervilhaca apresentou a 
menor eficiência agronômica dentre todas as espécies, mostrando-se de difícil controle e se não manejada corretamente pode interferir negativamente na cultura seguinte. Trabalhos como o presente caracterizam resultados que podem ser válidos na estruturação de um manejo adequado e focado em cada espécie utilizada em cobertura.

Tabela 2. Avaliação de eficiência agronômica em espécies de cobertura dessecadas com Zapp QI $^{\circledR}$ (ZQ) e Glyphosate 480 Agripec $^{\circledR}$ (GA), no município de Marechal Cândido Rondon/PR.

\begin{tabular}{|c|c|c|c|c|c|c|c|c|}
\hline \multicolumn{9}{|c|}{ Avaliações de eficiência agronômica } \\
\hline & \multicolumn{2}{|c|}{$4 \mathrm{DAD}^{1 /}$} & \multicolumn{2}{|c|}{$8 \mathrm{DAD}$} & \multicolumn{2}{|c|}{$16 \mathrm{DAD}$} & \multicolumn{2}{|c|}{$32 \mathrm{DAD}$} \\
\hline Tratamentos & ZQ & GA & ZQ & GA & ZQ & GA & ZQ & GA \\
\hline nabo-forrageiro & $16 \mathrm{Da}$ & $10 \mathrm{Db}$ & 48CDa & $38 \mathrm{CDb}$ & $94 \mathrm{Aa}$ & $85 \mathrm{Ab}$ & $100 \mathrm{Aa}$ & $88 \mathrm{Bb}$ \\
\hline aveia-preta & $52 \mathrm{Aa}$ & $40 \mathrm{Ab}$ & $77 \mathrm{Aa}$ & $65 \mathrm{Ab}$ & $86 \mathrm{Ba}$ & $79 \mathrm{Bb}$ & $99 \mathrm{Aa}$ & $92 \mathrm{Ab}$ \\
\hline azevém & $52 \mathrm{Aa}$ & $40 \mathrm{Ab}$ & $62 \mathrm{Ba}$ & $49 \mathrm{Bb}$ & $75 \mathrm{Ba}$ & $62 \mathrm{Cb}$ & $94 \mathrm{Ba}$ & $77 \mathrm{Cb}$ \\
\hline aveia-branca & $40 \mathrm{Ba}$ & $25 \mathrm{Bb}$ & $55 \mathrm{Ca}$ & $41 \mathrm{Cb}$ & $65 \mathrm{Ca}$ & $53 \mathrm{Db}$ & $93 \mathrm{Ba}$ & $86 \mathrm{Bb}$ \\
\hline ervilhaca & $23 \mathrm{Ca}$ & $14 \mathrm{Cb}$ & $44 \mathrm{Da}$ & $32 \mathrm{Db}$ & $62 \mathrm{Ca}$ & $46 \mathrm{~Eb}$ & $85 \mathrm{Ca}$ & $64 \mathrm{Db}$ \\
\hline $\mathrm{CV} \%$ & \multicolumn{2}{|c|}{4,88} & \multicolumn{2}{|c|}{6,40} & \multicolumn{2}{|c|}{3,25} & \multicolumn{2}{|c|}{2,30} \\
\hline
\end{tabular}

* Letras maiúsculas diferem entre si nas colunas e letras minúsculas nas linhas, pelo teste de Tukey $(\mathrm{p}<0,05) .{ }^{11}$ dias após a dessecação (DAD).

Na Figura 1 encontram-se as regressões lineares para o produto $\mathrm{ZQ}$, que ilustra sua ação sobre as espécies de cobertura ao longo do tempo na eficiência agronômica. A espécie que apresentou o maior coeficiente angular foi o nabo-forrageiro, seguido da ervilhaca. Destacase, portanto, que essas espécies foram as que apresentaram maior incremento diário de eficiência agronômica ao longo do tempo.
Segundo ajuste do modelo, no caso do naboforrageiro, a cada dia após a aplicação de ZQ a eficiência agronômica aumentou 2,787\%. Já na ervilhaca, a cada dia após a aplicação de ZQ a eficiência agronômica aumentou 2,056\%. Os menores valores diários de eficiência agronômica aconteceram nas espécies aveiapreta e azevém, com 1,4304 e 1,4543\%, respectivamente.

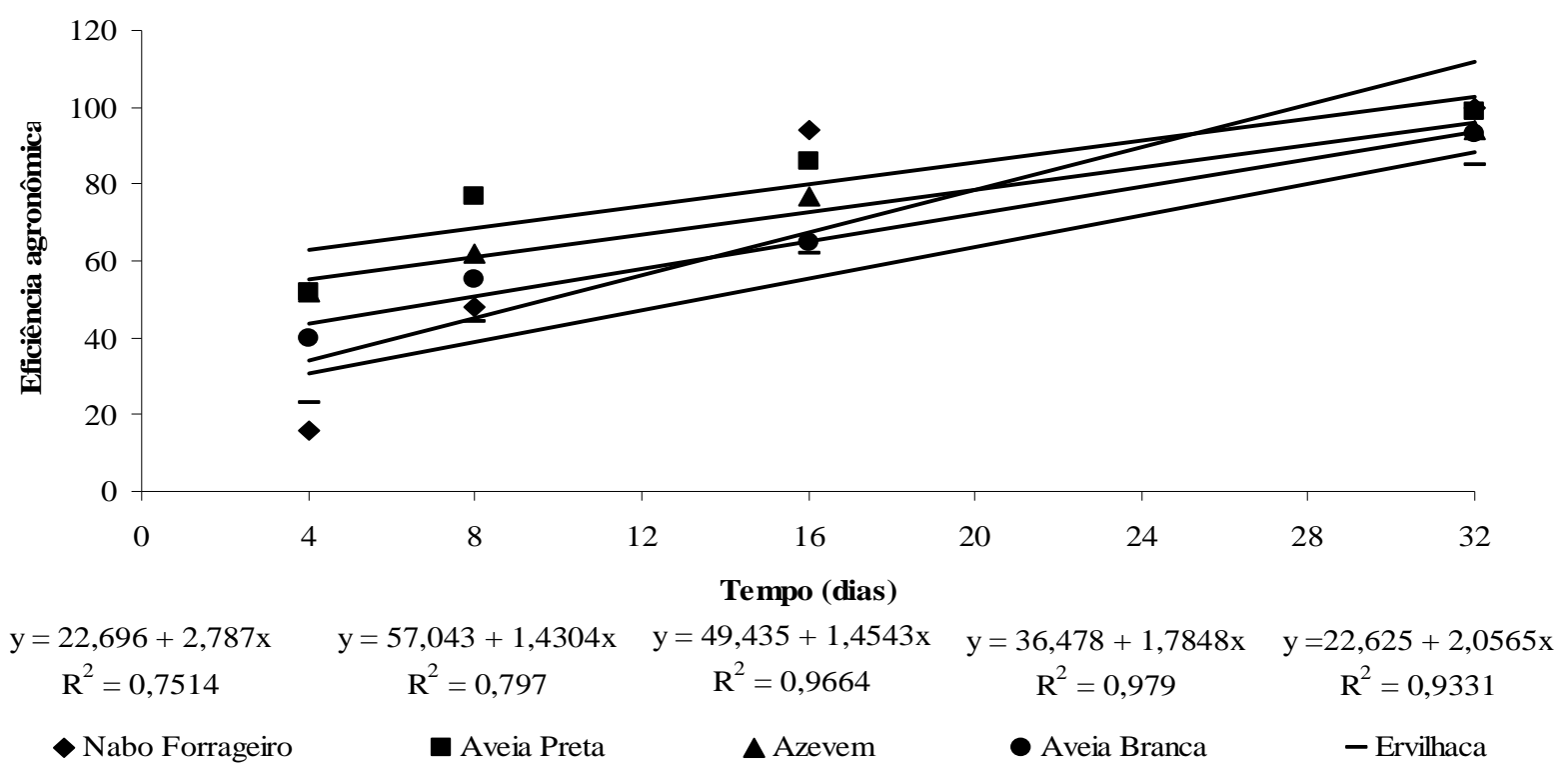

Figura 1. Eficiência agronômica de glyphosate com princípio ativo a base de sal de potássio (ZQ), aplicado em espécies de cobertura. 
O nabo-forrageiro apresentou coeficiente linear numericamente baixo em relação às demais espécies pelo fato dos sintomas aparecerem de forma mais tardia na planta. A planta apresenta características herbáceas, com intensa ramificação e altura variando entre 1,0 e $1,8 \mathrm{~m}$, com sistema radicular pivotante e agressivo (Brasi et al. 2008), o que podem favorecer o aumento do tempo para que o herbicida transloque por toda a planta, demonstrando seus efeitos de forma mais tardia, porém eficaz. Mesmo o naboforrageiro tendo um início lento de eficiência agronômica foi no final a espécie que apresentou a maior porcentagem diária de eficiência agronômica, o mesmo acontecendo com a espécie ervilhaca.

Na Figura 2 encontram-se as regressões lineares da ação do produto GA, sobre as espécies de cobertura ao longo do tempo na eficiência agronômica. Conforme ajuste das equações, novamente a espécie nabo-forrageiro apresentou o maior valor diário de ganho de eficiência agronômica $(2,6196 \%)$, seguido da aveia-branca $(2,0717 \%)$. O menor ganho de eficiência agronômica diária foi com a espécie azevém com $1,2783 \%$.

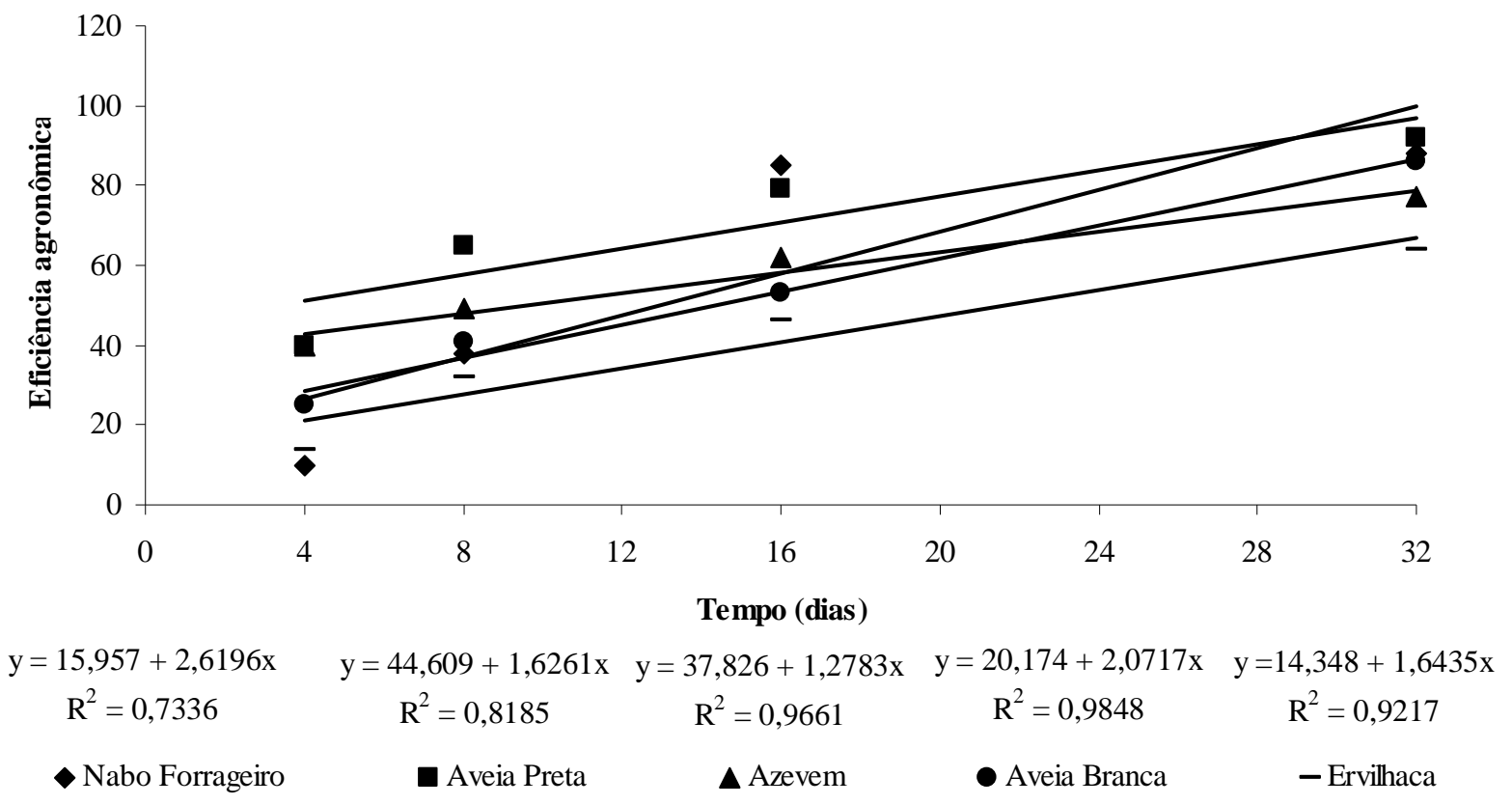

Figura 2. Eficiência agronômica de glyphosate com princípio ativo a base de sal de isopropilamina (GA), aplicado em espécies de cobertura.

Na comparação das espécies com seus respectivos coeficientes lineares, dentro de cada produtos temos a tendência dos resultados de GA serem menores em relação a ZQ, diferença essa atribuída principalmente ao sal de potássio (ZQ), que se mostra superior ao sal de isopropilamina (GA), algumas espécies mostraram-se mais tolerantes ao glyphosate, enquanto outras mais suscetíveis.

\section{Conclusões}

O Zapp Q $i^{\circledR}$ causou maior fitotoxicidade e proporcionou maior eficiência agronômica das espécies de cobertura em relação ao Glyphosate 480 Agripec $^{\circledR}$.

O Zapp Qi ${ }^{\circledR}$ aos trinta e dois dias após dessecação apresentou os maiores valores de eficiência agronômica. 
A ervilhaca demonstrou-se de difícil controle sob a aplicação dos dois produtos avaliados.

O nabo-forrageiro foi a espécie que apresentou os maiores valores diários de eficiência agronômica para ambos os produtos.

Torna-se possível com este trabalho afirmar que para um manejo mais eficiente de espécies de cobertura, o glyphosate com o ingrediente ativo sal de potássio é o mais indicado.

\section{Referências}

AMADO, T.J.C. et al. Potencial de culturas de cobertura em acumular carbono e nitrogênio no solo no plantio direto e a melhoria da qualidade ambiental. Revista Brasileira de Ciência do Solo, v.25, n.1, p.189-197, 2001.

BRASI, L.A.C.S., DENUCCI S., PORTAS A.A. Nabo- adubo verde, forragem e bioenergia. Disponível em: $<$ http://www.infobi bos.com/Artigos/2008_2/nabo/index.htm>Aces so em: 12 dez. 2012.

CALONEGO, J.C.; FOLONI, J.S.S.; ROSOLEM, C.A. Lixiviação de potássio da palha de plantas de cobertura emdiferentes estádios de senescência após a dessecação química. Revista Brasileira de Ciência do Solo, v.29, n.1, p.99-109, 2005.

CONSTANTIN, J. et al. Influência do glyphosate na dessecação de capim-braquiária e sobre o desenvolvimento inicial da cultura do milho. Planta Daninha, v.26, n.3, p.627-636, 2008.

EMBRAPA. Empresa brasileira de pesquisa agropecuária. Sistema de classificação dos solos. Embrapa solos, $2^{\circ}$ ed. Rio de Janeiro, 2006.

\section{EUROPEAN WEED RESEARCH COUNCIL.}

Report of the 3rd and 4 rd meetings of EWRC Committee of methods in weed research. Weed Research, v.4, p.88, 1964.
FERREIRA, D.F. Sistema de análise de variância (Sisvar). Versão 4.6. Lavras: Universidade Federal de Lavras, 1999.

FURLANI, C.E.A. et al. Cultura do milho em diferentes manejos de plantas de cobertura do solo em plantio direto. Revista de Biologia e Ciências da Terra, v.7, n.1, p.161-167, 2007.

GALLI, A.J.B.; MONTEZUMA, M.C. Alguns aspectos da utilização do herbicida glifosate na agricultura. São Paulo: Monsanto do Brasil, 2005. 60 p.

JAKELAITIS, A. et al. Efeitos da chuva sobre a eficacia de formulacões de glyphosate no controle de Brachiaria decumbens). Revista Ceres, v.50, n 290, p.461-469. 2003.

KÖPPEN, W.; GEIGER, R. Klimate der Erde. Gotha: Verlag Justus Perthes. 1928. Wall-map $150 \mathrm{~cm} \times 200 \mathrm{~cm}$.

MARTINI, G.; PEDRINHO JR, A.F.F.; DURIGAN, J.C. Eficácia do herbicida glyphosate-potássico submetido à chuva simulada após a aplicação. Bragantia, v.62, n.1, p.39-45, 2003.

MELLO, I. Plantio direto e o agronegócio sustentável na metade sul do Rio Grande do Sul. Boletim Informativo FEBRAPDP, n.6, p. 1-2. 2002. Disponível em: <http:/ /www. febrapdp. org.br/informe_6_pagina_3.htm> Acesso em: 07 de junho de 2012.

MIYAZAWA, M.; PAVAN, M.A.; FRANCHINI, J.C. Neutralização da acidez do perfil do solo por resíduos vegetais. Informativo Agronômico, n.92, p.1-8, 2000.

MONQUERO, P.A. et al. Intervalo de dessecação de espécies de cobertura do solo antecedendo a semeadura da soja. Planta Daninha, v.28, n.3, p.561-573, 2010

PERIN, A.; SANTOS, R.H.S.; URQUIAGA, S.; GUERRA, J.G.M.; CECON, P.R. Produção de fitomassa, acúmulo de nutrientes e fixação biológica de nitrogênio por adubos verdes em cultivo isolado e consorciado. Pesquisa 
Agropecuária Brasileira, v.39, n.1, p.35-40, 2004.

ROMAN, E.S. et al. Resistência de azevém (Lolium multiflorum) ao herbicida glyphosate. Planta Daninha, v.22, n.2, p.301-306, 2004.

ROSOLEM, C.A.; CALONEGO, J.C.; FOLONI, J.S.S. Potassium leaching from millet straw as affected by rainfall and potassium rates. Communications in Soil Science and Plant Analysis, v.36, n.7/8, p.1063-1074, 2005.

SOCIEDADE BRASILEIRA DA CIÊNCIA DAS PLANTAS DANINHAS. Procedimentos para instalação, avaliação e análise de experimentos com herbicidas. SBCPD, 1995. 42p.

SOUZA, C.F.L. et al. Eficiência de diferentes herbicidas na dessecação de três espécies vegetais para a cobertura do solo. Revista Brasileira de Herbicidas, v.1, n.1, p.57-60, 2000.

ZAGONEL, J.; MAROCHI, A.I. Épocas e modos de aplicação de glifosato na dessecação de coberturas verdes de inverno para semeadura do milho. Boletim Informativo SBCPD, v.10. 2004, p.126. 